\title{
Discriminated Sidman avoidance behavior by guinea pigs
}

J. D. KEEHN AND C. D. WEBSTER

ALCOHOLISM AND DRUG ADDICTION RESEARCH FOUNDATION, TORONTO

Three guinea pigs learned to postpone signalled electric shocks by pressing a bar. Although bar holding served to postpone shocks, the animals, unlike rats, did not bar-hold indefinitely. There was evidence of "avoidance decrement" in that shock densities increased with training, but this was not accompanied by a comparable decrease in response rate.

In the normal Sidman (1953) avoidance training procedure bar holding is non-functional and hence is punished when it occurs. The present experiment elucidates the development and maintenance of discriminated avoidance behavior by guinea pigs when bar holding is permitted without penalty.

\section{Subjects}

Three male white guinea pigs were used as Ss. They weighed 405 (S1), 450 (S2) and 400 (S16) gm and were 6 to 8 weeks old.

\section{Apparatus}

The animals' working space was 5 in. wide, 11-1/2 in. long and 7-5/8 in. high approximately. The space contained a single bar the top of which was 3-3/4 in. above the chamber floor and a white stimulus light slightly above and about 1-1/2 in. to the right of the bar. The bar was 2 in. wide and protruded $5 / 8$ in. from the chamber wall. A weight of about $20 \mathrm{gm}$ on the bar was sufficient to activate the automatic programming and recording equipment.

A Grason-Stadler shock generator was used to apply brief (.3 sec.) scrambled shocks to the grid floor of the experimental chamber. The generator output was set at $2 \mathrm{~mA}$. Response records were obtained on two cumulative recorders. One recorder stepped with every bar press. The other stepped with every bar press and continued to step every .2 sec. that the bar was held down.

\section{Procedure}

Shocks were programmed to recur every $5 \mathrm{sec}$. (SS interval) unless a response was made to the bar. Bar responses postponed shocks for $20 \mathrm{sec}$. from the time the bar was released. A signal (tone and light) preceded shocks by $5 \mathrm{sec}$. (LS interval). Every response terminated the signal and postponed its next onset for $15 \mathrm{sec}$. from the time the bar was released (RL interval). After each response, then, there was an RL interval in which shocks were never received, an LS interval which was terminated by either a response or a shock, and an SS interval in which shocks were received in the presence of a signal until a response was made. Responses in the $R L$ interval prolonged the interval; those in the LS and SS inter- vals reinstated the $R L$ interval.

All animals were given two 4-hr. training sessions. In the first few minutes of Session 1 responses to the bar were shaped by the experimenter terminating the SS interval when an animal approached the bar. Results

Figure 1 contains cumulative bar pressing and holding data generated by animal S1 in its first training session. The bar pressing record is conventional. The holding record was obtained by making the pen step all the time the bar was held down. In the beginning most shocks occurred in blocks at SS intervals. The response to terminate these muns of shocks was shaped by the experimenter. Shaping stopped at N. For the next few minutes the animal continued to take multiple shocks for each signal onset but it soon came to press and hold the bar after only one or two shocks following each signal. The avoidance behavior of terminating the sequence of shocks in the SS interval was the first to develop. However, each response to the bar not only terminated the signal but also postponed its next appearance according to the time the bar was depressed. Increasing bar holding times are evident in Fig. 1, with the first long hold occurring at 0 . Bar presses in the RL interval also postponed signal onset. Some behavior of this kind in the form
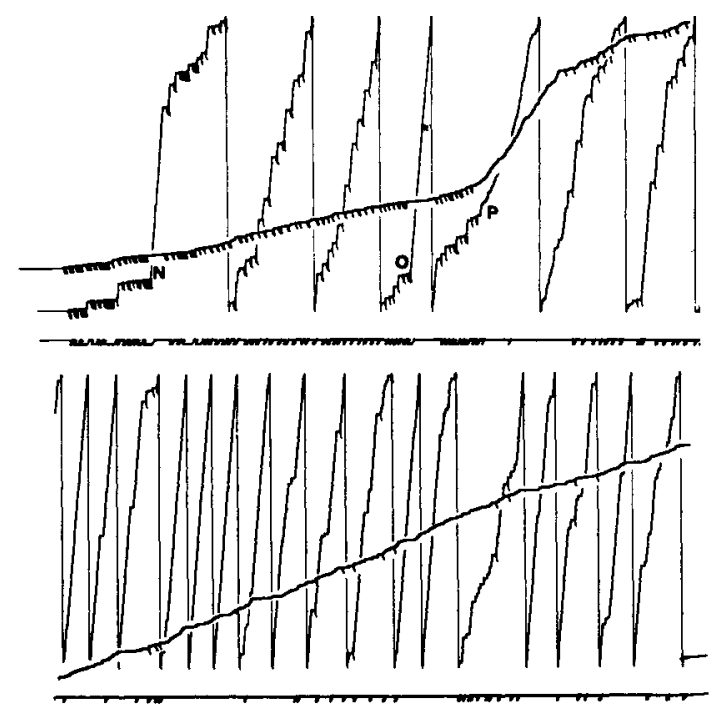

Fig. 1. Cumulative bar pressing (low rate) and bar holding (high rate) of animal $\mathbf{S 1}$ during the first (upper reconds) and last (lower records) hr. of its first training session. Shocks are indicated by lateral spurs on both records. Downward deflections of the horizontal traces mark signal onsets. 
Table 1. Signal onsets and per cent signalled shocks avoided in successive $30 \mathrm{~min}$. periods.

Per cent avoidance per $30 \mathrm{~min}$. period.

$\begin{array}{llllllll}1 & 2 & 3 & 4 & 5 & 6 & 7 & 8\end{array}$

Animal $\mathbf{S 1}$

Session 1:

$\begin{array}{lllllllll}\text { Signals } & 41 & 33 & 15 & 12 & 42 & 11 & 13 & 22\end{array}$

$\begin{array}{lllllllll}\% \text { avoidance } & 0.0 & 6.1 & 53.3 & 83.3 & 57.1 & 81.9 & 61.5 & 63.6\end{array}$

Session 2:

$\begin{array}{lllllllll}\text { Signals } & 21 & 23 & 45 & 29 & 32 & 40 & 32 & 51\end{array}$

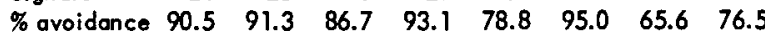

Animal 52

Session 1:

$\begin{array}{lllllllll}\text { Signals } & 30 & 23 & 30 & 32 & 36 & 48 & 38 & 65\end{array}$

$\begin{array}{lllllllll}\text { \% avoidonce } & 6.7 & 4.3 & 33.3 & 56.3 & 58.3 & 58.3 & 55.3 & 55.4\end{array}$

Session 2:

$\begin{array}{lrrrrrrrr}\text { Signals } & 45 & 47 & 36 & 32 & 49 & 41 & 36 & 36\end{array}$

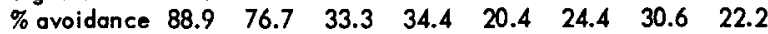
Animal 516

Session 1:

$\begin{array}{lllllllll}\text { Signals } & 20 & 7 & 14 & 17 & 10 & 17 & 11 & 35\end{array}$

$\begin{array}{lllllllll}\text { \% avoidance } & 0.0 & 14.3 & 42.9 & 58.8 & 60.0 & 88.2 & 81.8 & 94.3\end{array}$

Session 2:

$\begin{array}{lllllllll}\text { Signals } & 58 & 80 & 80 & 77 & 85 & 84 & 71 & 92\end{array}$

\begin{tabular}{lllllllll}
$\%$ avoidance & 97.3 & 96.3 & 97.5 & 85.7 & 89.4 & 85.7 & 73.4 & 80.4 \\
\hline
\end{tabular}

of brief presses began at $P$ in Fig. 1, but signal postponement was more frequently achieved by bar bolding. Signal onsets and durations are shown by depressions in the bottom line of Fig. 1 .

Table 1 shows the number of times each $S$ allowed the signal to appear in successive $30-\min$. periods in

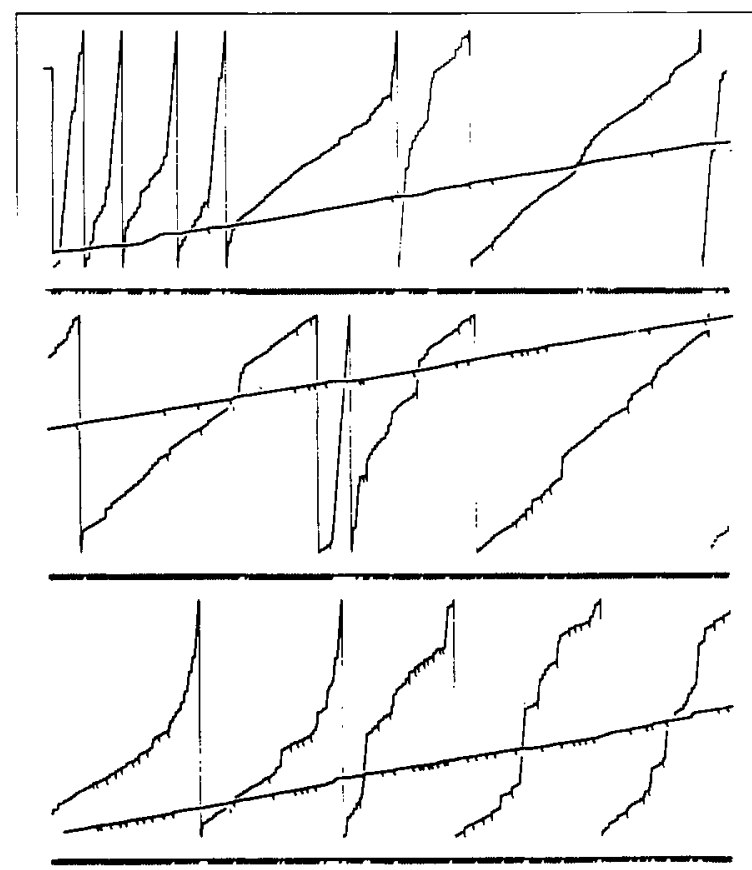

Fig. 2. Cumulative bar pressing (low rate) and bar holding (high rate of animal $\mathbf{s 1 6}$ during the whole of its second training session. Both records begin at the upper left and continue through to the lower right. Shocks are indicated by lateral spurs on both records. Downward deflections of the horizontal traces mark signal onsets. both training sessions, as well as the percentages of signalled shocks avoided. The same general behavior was exhibited by all the animals; at first signals appeared frequently and were almost always followed by shock, then they appeared less frequently and were less often followed by shock and then signal density increased but most signals were not followed by shock. However, all animals exhibited a decrement in shock avoidance from the beginning to the end of Session 2. The most successful sustained shock avoidance was exhibited by animal S16. Its complete Session 2 cumulative bar pressing and bar holding records are shown in Fig. 2. An increase in shock density toward the end of the session is apparent. In spite of this the bar pressing record shows no gross change in rate of response. What changed was the stimulus that occasioned the response. At first it was the signal alone but later it was often the signal and recent occurrence of a shock. The bar holding record shows the rapid elimination of long duration responses and their occasional reappearance at points throughout the session.

\section{Discussion}

All Ss acquired avoidance behavior very quickly. Shock density was reducible by responses in the RL, LS and SS intervals, and either bar pressing or bar holding served to prolong the RL interval. In spite of this, responses in the $\mathrm{RL}$ interval dropped out almost entirely and most responses usually occurred in the LS interval. However, every animal responded less in the LS and more in the SS interval as Session 2 progressed. Considered from the point of view of their success in avoiding shock every animal exhibited a decrement within Session 2. But from the standpoint of the amount of behavior occasioned by the reinforcement schedule no decrement occurred, because the rate of response emission showed no noticeable falloff. What changed systematically was the stimulus conditions under which responses were emitted; at first almost all responses were emitted shortly after signal onset, but gradually more and more of them were emitted in the presence of the signal and a recently received shock. This could only have come about through the differential consequences of responding in the two intervals. The objective consequences of bar presses in LS and SS intervals were the same; in both cases a response within 5 sec. reinstated the RL interval and failure to respond was followed by shock 5 sec. after the interval began. Whatever differential consequences there were, then, must have derived from the shocks the animals received in the Ss intervals. The most obvious consequence of shock is pain, and coincidental termination of pain with a bar press in the SS interval could have reinforced the response in this interval differentially with respect to a response made in the LS interval.

\section{Reference}

Sidman, M. Avoidance conditioning with brief shock and no exteroceptive warning signal. Science, 1953, 118, 157-158. 